and examples from elsewhere to help us take a less blinkered view.

Because mangrove and saltmarsh ecosystems are both wetlands, and found in estuaries, Mangroves and Saltmarshes may have difficulty finding a niche. Numerous established journals cover similar themes, including: Estuaries; Wetlands; Aquatic Botany; Estuarine, Coastal and Shelf Science; and CoastalZone Management Journal.

I hope Mangroves and Saltmarshes succeeds. I believe it can fill an important role for the research, and especially, resource management communities in developing and developed countries alike.

Thomas J. Smith III is at the US Geological Survey, Biological Resources Division, OE Building, Room 148, Florida International University, Miami, FL 33199, USA.

\section{Human interest stories}

\author{
Applied Geographic Studies \\ Editor Milton E. Harvey \\ John Wiley and Sons. 4/yr. USA \$155, \\ elsewhere \$179 (institutional); USA \$70, \\ elsewhere $\$ 94$ (personal) \\ Michael Batty
}

Geography emerged as an academic discipline at the height of imperialist expansion in the late nineteenth century, but by the 1960s it had lost its taste for describing regions and landscapes in meticulous detail in favour of more systematic inquiry. It divided into human geography, which drew on theory and method in the social sciences, particularly economics, and physical geography, which oriented itself towards the earth sciences.

The subject has softened its scientific stance since then, moving away from a search for strong theory, becoming more pragmatic

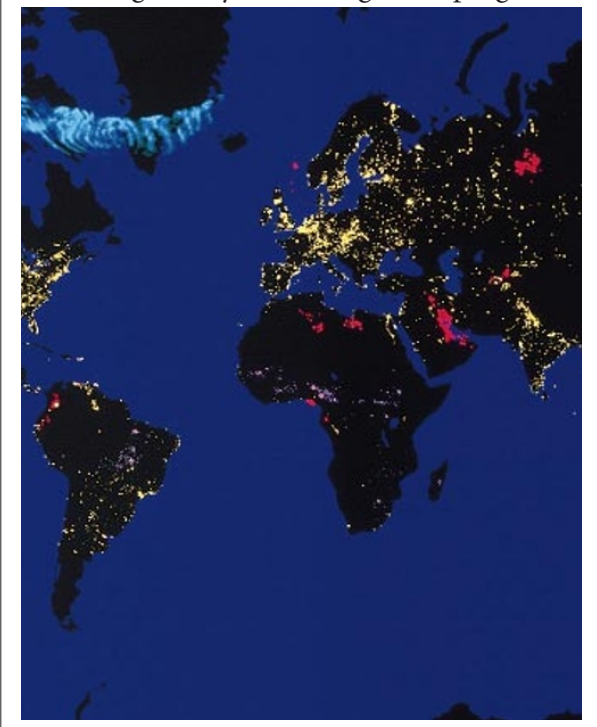

Night lights: cities, burning vegetation (purple), oil flares (red) and the aurora borealis (light blue). and, in the process, taking on a multitude of applications.

Applied Geographic Studies was launched last year in response to such developments. Building on a series of successful conferences that drew together a diversity of geographic applications, its content reflects contemporary human issues that have important geographical dimensions. Environmental problems, such as the spatial distribution of pollutants and their implications for disease and health care, are of concern; also relevant to this focus is the use of geographical models for marketing and retailing, for problems posed by the impact of ageing, and for the provision of housing. The journal covers population studies involving urbanization, migration and the current problems of global geopolitics, although so far there is little discussion about the traditional areas of urban planning and transportation.

Starting a journal such as this is a hazardous undertaking, because a competitor (Applied Geography) has existed for a dozen or more years, and several others specialize in the subject. But the editor has assembled an impressive editorial board of 32 well-known academic geographers who are involved in applications, and nearly half of these have been enticed to write in the four issues that make up the first volume.

The result is a useful and balanced collection of competent articles that reflect the intended range. The articles are quiet and unpretentious as is the style and presentation of the journal. If the editor and board are able to keep up this momentum, then Applied Geographic Studies will soon become an established outlet for geographic applications of quality.

Michael Batty is at the Centre for Advanced Spatial Analysis (CASA), University College London, 1-19 Torrington Place, London WC1E 6BT, UK.

\section{Civil defence in the war against AIDS}

\section{AIDS and Behavior}

Editor Thomas L. Patterson

Plenum. 4/yr. USA \$150, elsewhere $\$ 175$ (institutional); USA $\$ 50$, elsewhere $\$ 59$ (personal)

\section{RalphJ.DiClemente}

While there have been great advances in the understanding and treatment of HIV, there is, at present, no cure. And, while promising candidate vaccines are being readied for testing, an effective, widely available vaccine is not anticipated in the foreseeable future. Thus, primary prevention of HIV transmission is of paramount importance in curtailing the pandemic.

The behavioural and social sciences have played and will continue to play a critical role

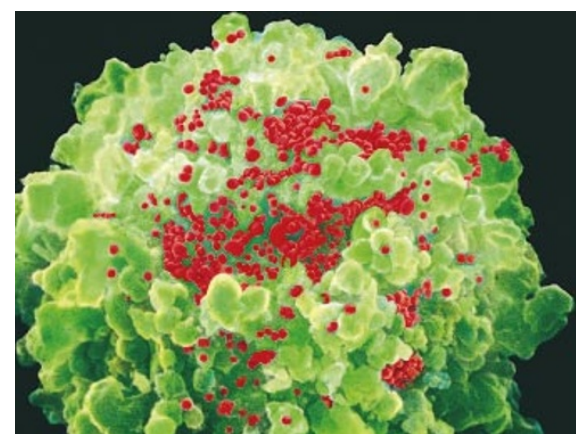

HIV particles budding from an infected T-cell.

in understanding the factors associated with HIV-related risk behaviours, both sexual and drug-related, and in the development of interventions designed to reduce such behaviours among HIV seronegative as well as HIV seropositive individuals.

The role of these sciences, however, is not limited to changing behaviour that might lead to infection. They also play a key role in understanding factors associated with medication adherence, with understanding an individual's coping response, with identifying the neuropsychological impact of HIV infection on cognitive functioning, and with examining the emotional effects of HIV such as depression. Such understanding can help in the development of interventions which will improve people's lives in all these areas.

HIV-related behavioural and social research was often published in broad-based public health journals or more clinically focused HIV publications, but the growth in such research makes AIDS and Behavior a welcome new vehicle for its dissemination.

The journal has an outstanding editorial board, a veritable Who's Who of the field. Many of the articles are empirically based rather than theoretical reviews or commentaries, but non-empirical articles are also welcomed. Emerging areas of research are more fully explored by groups of five to seven thematically linked papers co-ordinated by a guest editor, usually an expert in that particular area.

Topics span the gamut from primary to secondary prevention, adjustment to living with HIV, and the influence of a host of psychosocial factors on risk behaviour and adherence. The research is of high quality, perhaps reflecting the fact that many of the contributing authors are inveterate investigators. The journal is attractive and well formatted, with clear text, tables and figures. Articles are usually from eight to ten pages long, although longer articles are also published; turnaround time is satisfactory.

Anyone interested in this area of HIV research will be well served by examining AIDS and Behavior.

Ralph J. DiClemente is in the Department of Behavioral Sciences and Health Education, Rollins School of Public Health, Emory University, Atlanta, GA 30322, USA. 